\title{
Article \\ Measurement of Neutron Dose Equivalent within and Outside of a LINAC Treatment Vault Using a Neutron Survey Meter
}

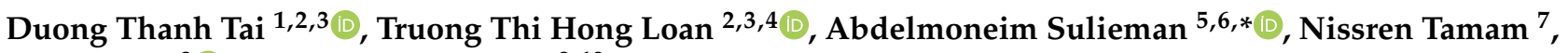 \\ Hiba Omer 8 (D) and David A. Bradley ${ }^{9,10}$
}

1 Department of Industrial Electronics and Biomedical Engineering, Faculty of Electrical and Electronic Engineering, Ho Chi Minh City University of Technology and Education, Ho Chi Minh City 749000, Vietnam; taidt@hcmute.edu.vn

2 Faculty of Physics and Engineering Physics, University of Science, Ho Chi Minh City 700000, Vietnam; tthloan@hcmus.edu.vn

3 Vietnam National University, Ho Chi Minh City 749000, Vietnam

4 Nuclear Technique Laboratory, University of Science, Ho Chi Minh City 749000, Vietnam

5 Radiology and Medical Imaging Department, College of Applied Medical Sciences, Prince Sattam Bin Abdulaziz University, Alkharj 11942, Saudi Arabia

6 Basic Science Department, College of Medical Radiologic Science, Sudan University of Science and Technology, Khartoum 11111, Sudan

7 Physics Department, College of Sciences, Princess Nourah Bint Abdulrahman University, Riyadh 11671, Saudi Arabia; nmtamam@pnu.edu.sa

8 Department of Basic Sciences, Deanship of Preparatory Year and Supporting Studies, Imam Abdulrahman Bin Faisal University, Dammam 34212, Saudi Arabia; hbomer@iau.edu.sa

check for updates

Citation: Tai, D.T.; Loan, T.T.H.; Sulieman, A.; Tamam, N.; Omer, H.; Bradley, D.A. Measurement of Neutron Dose Equivalent within and Outside of a LINAC Treatment Vault Using a Neutron Survey Meter. Quantum Beam Sci. 2021, 5, 33. https://doi.org/10.3390/ qubs5040033

Academic Editor: William L. Dunn

Received: 6 October 2021

Accepted: 23 November 2021

Published: 30 November 2021

Publisher's Note: MDPI stays neutral with regard to jurisdictional claims in published maps and institutional affiliations.

Copyright: (c) 2021 by the authors. Licensee MDPI, Basel, Switzerland. This article is an open access article distributed under the terms and conditions of the Creative Commons Attribution (CC BY) license (https:// creativecommons.org/licenses/by/ $4.0 /)$.
9 Centre for Nuclear and Radiation Physics, Department of Physics, University of Surrey, Guildford GU2 7XH, UK; d.a.bradley@surrey.ac.uk

10 Centre for Applied Physics and Radiation Technologies, School of Engineering and Technology, Sunway University, No. 5 Jalan Universiti, Bandar Sunway, Petaling Jaya 47500, Malaysia

* Correspondence: a.sulieman@psau.edu.sa

\begin{abstract}
This work concerns neutron doses associated with the use of a Siemens Primus M5497 electron accelerator, which is operated in the photon mode at $15 \mathrm{MV}$. The conditions offer a situation within which a fraction of the bremsstrahlung emission energies exceed the photoneutron threshold. For different field sizes, an investigation has been made of neutron dose equivalent values at various measurement locations, including: (i) At the treatment table, at a source-surface distance of $100 \mathrm{~cm}$; (ii) at the level of the floor directly adjacent to the treatment table; and (iii) in the control room and patient waiting area. The evaluated neutron dose equivalent was found to range from 0.0001 to $8.6 \mathrm{mSv} / \mathrm{h}$, notably with the greatest value at the level of the floor directly adjacent to the treatment couch $(8.6 \mathrm{mSv} / \mathrm{h})$ exceeding the greatest value on the treatment table $(5.5 \mathrm{mSv} / \mathrm{h})$. Low values ranging from unobservable to between 0.0001 to $0.0002 \mathrm{mSv} / \mathrm{h}$ neutron dose were recorded around the control room and patient waiting area. For measurements on the floor, the study showed the dose equivalent to be greatest with the jaws closed. These data, most particularly concerning neutron distribution within the treatment room, are of great importance in making steps towards improving patient safety via the provision of protective measures.
\end{abstract}

Keywords: neutron dosimetry; secondary cancer; linear accelerator; radiation therapy

\section{Introduction}

Worldwide, cancer incidence has been on the rise, presently running at in excess of 19.3 million new cases annually, increasing with population growth and aging. Cancer is a leading cause of death and a major impediment towards further increase in life expectancy within the general population [1]. Various treatment options are available, according to the type and tumor stage, including surgery, chemotherapy, immunotherapy, radiation therapy, radiofrequency ablation, targeted therapy, and cryoablation [2], some of these are 
conducted in combination. Worldwide, to a greater extent at many of the more substantial hospitals, radiation therapy techniques are one of a number of approaches on offer towards treating cancer. Indeed, radiation therapy forms a highly important part of cancer treatment, with about $50 \%$ of cancer patients receiving it at some point during the management of their disease, also accounting for about $40 \%$ of cancer cures [3].

External photon beam radiation therapy is for the most part dominated by the use of medical electron linear accelerators (LINAC). In this, the accelerated electron beam is made to impact on a high atomic number target of high melting point, delivering penetrating X-rays (bremsstrahlung radiation). Although an accelerating potential of $6 \mathrm{MV}$ is popularly used, LINACS offering potentials of up to $20 \mathrm{MV}$ are also available for treatments, especially deep-seated tumors. The various energies of X-rays can be harnessed in making use of several types of techniques, including three-dimensional conformal radiation therapy (3DCRT), intensity modulated radiation therapy (IMRT), stereotactic radiosurgery (SRS), and volumetric modulated arc therapy (VMAT) [4]. X-rays at potentials of greater than $10 \mathrm{MV}$ can be used for the treatment of deep-seated tumors, as previously mentioned, a situation within which a fraction of the bremsstrahlung emission energies exceeds the photoneutron threshold. In use of these high X-ray energies, the generation of secondary neutrons via photonuclear reactions can be expected, produced in the various materials comprising the accelerator head and its components, including the target, filter, collimator, and jaws of the accelerator, all of the items containing heavy isotopes [5]. In exceeding the threshold for neutron separation in these heavy nuclei, the consequent neutron doses may pose a risk to patients, also to the others surrounding the radiation area, in particular the workforce. Indeed, in the treatment of tumors at these elevated MV values, one serious risk that is worthy of contemplation is second cancer induction, a result of the undesired secondary neutrons component [6]. The patient's age, amount of radiation dose, and volume of normal tissue irradiated are among the main factors that influence second malignancy risk [7]. The radiobiological effectiveness of a neutron differs depending on its energy. In these circumstances, fast and thermalized components are both important in spectral distribution of neutrons around a therapy linear accelerator.

Mitigation of secondary neutrons can improve the treatment efficiency, in part by reducing the radiocarcinogenic risk of radiation therapy that results from the high-quality factor of the thermal neutron component. Moreover, in regard to neutron irradiation, paediatric patients have a greater risk of second cancer incidence. Subsequent to the course of radiation therapy, a value of up to $19 \%$ is estimated at 30 years of age, with longer life expectancy and sensitive tissues taken into account [8-10]. The photon beams generated at about $10 \mathrm{MV}$ and the greater neutrons can be expected to contribute at a low fraction to the patient's dose, accordingly with the increase in secondary cancer risk. For this reason, it is not considered in most dosimetric assessments [6]. Additionally, patient tissue can be activated by neutrons, composed as these tissues are of different stable elements, notably with $\mathrm{C}, \mathrm{H}, \mathrm{O}, \mathrm{N}$, and $\mathrm{Ca}$ accounting for the greatest weight percentage [11]. It is further well known that short-lived activation products, such as 27Al (half-life $2.3 \mathrm{~min}$ ), can result, should care not be taken in choosing the best considered constructional material of the couch and walls of the bunker. These circumstances require a short cooling off period prior to the bunker entry post treatment. Previous studies have also shown that the neutron production in the treatment rooms during patient treatment with photon energies $\geq 15 \mathrm{MV}$ are significant and, additional shielding is necessary [12-15]. Given this background, it is necessary to investigate the equivalent dose arising from these neutrons production, not least in order to mitigate the risk to the healthy tissues that surround the tumors. This work investigates the neutron dose equivalent for different field sizes at various measurement locations in the radiotherapy department, primarily within the bunker.

\section{Materials and Methods}

A direct measurement of equivalent dose rate produced by neutrons from a Siemens Primus M5497 electron accelerator was performed at the Department of Nuclear Medicine 
and Radiation Therapy, Dong Nai General Hospital in Vietnam. The particular LINAC offers six electron energies, 5.0, 7.0, 8.0, 10.0, 12.0, and 14.0 and two photon beam energies (6 and $15 \mathrm{MV}$ ). The LINAC delivers the following monitor units (MU): 200, 400, 600, 800 , and 1000. Due to the fixed construction of the other components in this LINAC, the secondary neutrons investigated herein are mainly due to the LINAC jaw openings. The equivalent dose rates of neutrons generated via photonuclear reactions $(\gamma, \mathrm{n})$ in the component materials of the jaw were quantified at different positions in the therapy room (Figures 1 and 2), obtained for various jaw opening sizes, including fully closed. Moreover, the equivalent dose-rate estimation is included at the maze to the LINAC bunker and at key positions outside of the bunker.

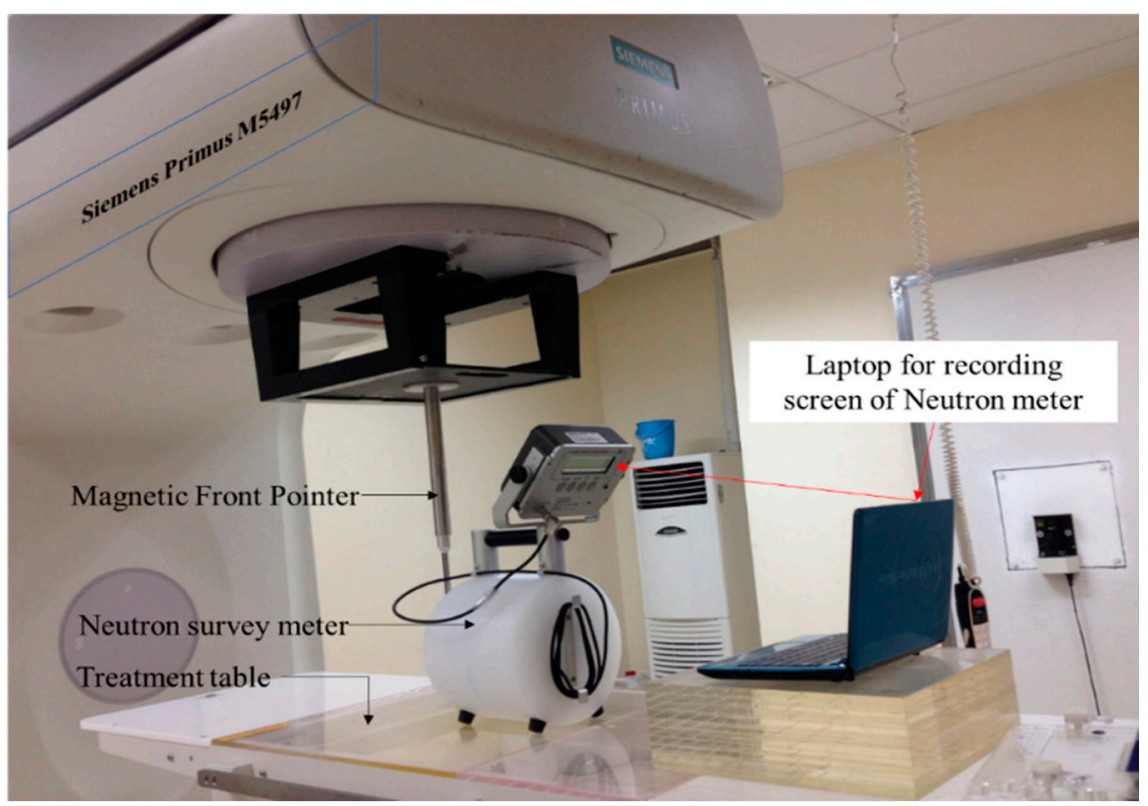

Figure 1. Measurement setup for secondary neutron dosimetry at a radiotherapy linear accelerator.

\subsection{Dose Measurement}

The experiment was performed at the following locations: (i) At the treatment table with a source-surface distance of $100 \mathrm{~cm}$; (ii) on the floor adjacent to the treatment couch; and (iii) at the control room and patient waiting area. The measurement geometry is illustrated in Figure 2. To estimate the dependence of the secondary neutron doses on the energy of photons, measurements were performed at 6 and $10 \mathrm{MV}$. The photon intensity was measured in terms of <intensity> photons/s. The various field size measurements made at each point, each averaged over a period of $5 \mathrm{~min}$. The field sizes of the jaw were: (i) $0 \times 0$ (closed jaw), $5 \times 5,10 \times 10,15 \times 15$, and $20 \times 20 \mathrm{~cm}^{2}$ (the widest setting). In radiotherapy practice, various radiation beams are needed for seeking the adequate cover of the treatment volume. An advantage in the use of high-energy beams includes the treatment with higher accuracy to deeper tumors, while sparing the skin from the tissue reaction effect.

\subsection{Detector}

The neutron dose equivalent rate measurement was measured using a Meridian neutron survey meter (Model 5085), as shown in Figure 3. The Meridian instrument has a wide energy and dose-rate equivalent rate response, the latter ranging from 0.1 to $100 \mathrm{mSv} / \mathrm{h}$, obtained with high accuracy, within 1\%. The detector has two operational modes (rate and integrate) with an audible sound of frequency of $2.4 \mathrm{kHz}$. The system is equipped with a boron trifluoride (BF3) gas detector (to provide for $10 \mathrm{~B}(\mathrm{n}, \alpha) 7 \mathrm{Li}$ ) with boron used as a rounded moderator to strengthen the detector response to any fast neutrons. One end of the moderator is rounded to give a better directional response. 


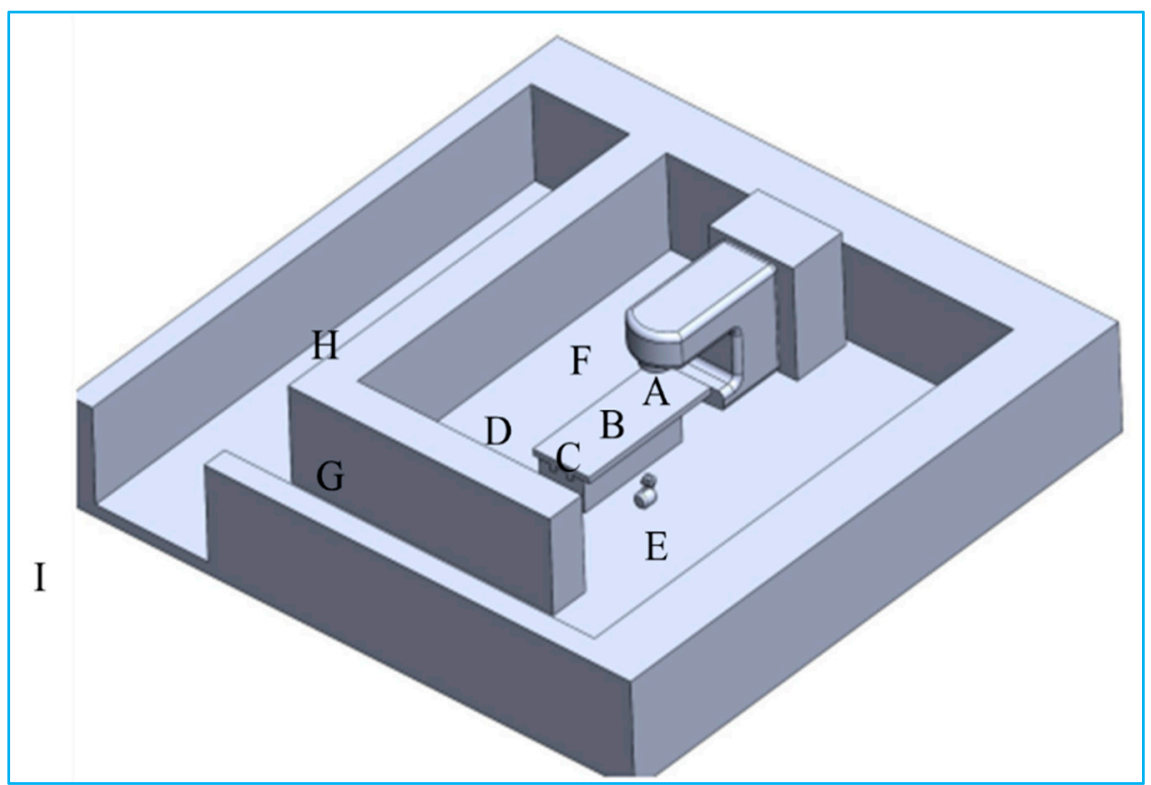

Figure 2. Location of Meridian neutron survey meter (points A-I) for the neutron fluence measurement.

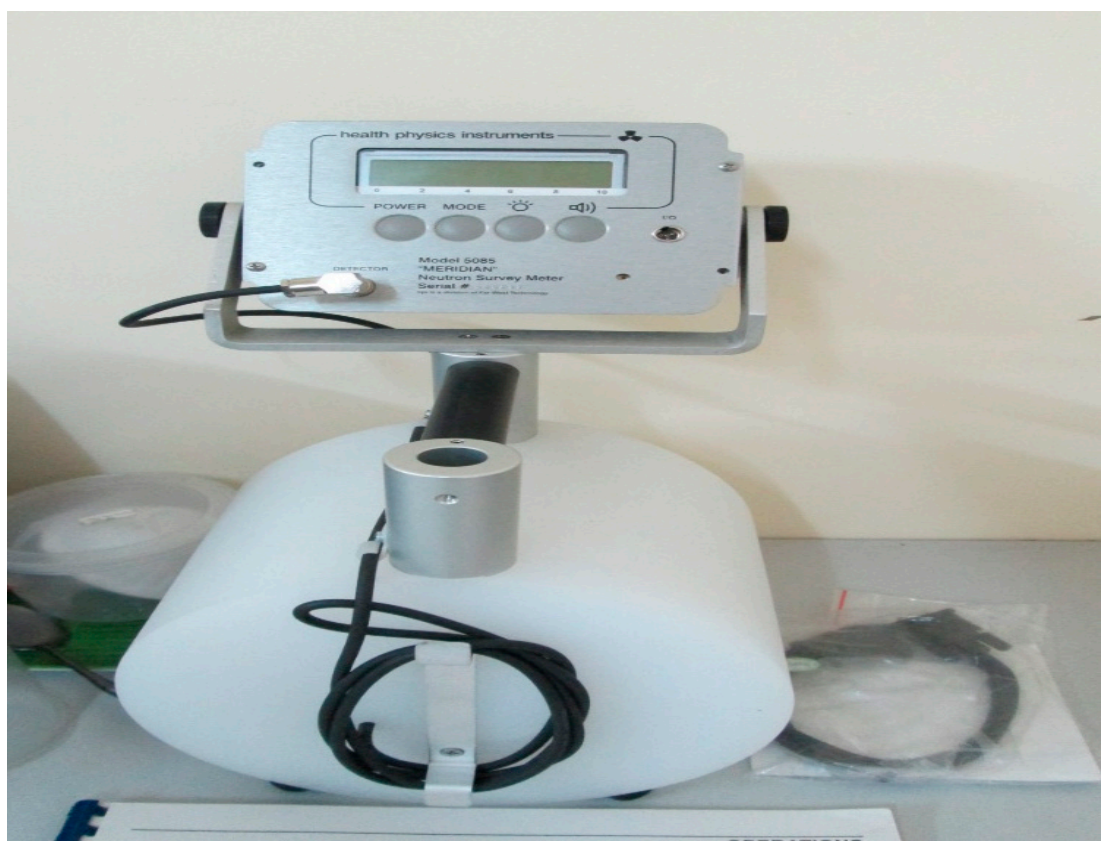

Figure 3. Meridian neutron survey meter (Model 5085).

\section{Results and Discussion}

In the present study, the neutron dose equivalent rate is quoted in $\mathrm{mSv} / \mathrm{h}$. During LINAC delivered external beam photon radiation therapy, the incident electron beam impinges upon a target of high atomic number $(Z)$ producing bremsstrahlung. Then, the photons impinge on collimators (primary and secondary) and other high $\mathrm{Z}$ media within the LINAC head generating neutrons (with a conventionally understood threshold of $\geq 8 \mathrm{MeV}$ ). The primary and secondary collimators comprise two arrays of moveable high- $\mathrm{Z}$ material jaws. With a closed collimator and measurements made at floor level, the recorded neutron dose equivalent ranged from as low as $0.0001 \mathrm{mSv} / \mathrm{h}$ outside of the bunker to $8.6 \mathrm{mSv} / \mathrm{h}$ at the maze end closest to the LINAC, exceeding the maximum found on the treatment table at the largest open-jaw settings $(5.5 \mathrm{mSv} / \mathrm{h})$. The latter is at a source-surface distance of $100 \mathrm{~cm}$. In the control room and patient waiting areas, the neutron dose at less 
than the detection limit was typical. The dose equivalent was greatest when the jaws were closed, with the measurements made on the floor.

The results of radiation dose equivalent are presented in Tables 1 and 2. Table 1 shows the neutron dose equivalent rate (in $\mathrm{mSv} / \mathrm{h}$ ) at locations $\mathrm{A}, \mathrm{B}$, and $\mathrm{C}$, quoted as a function of field size. The dose-rate equivalent depends on the field size and not on the position along the $\mathrm{y}$-axis (Figure 4). The equivalent dose-rates (in $\mathrm{mSv} / \mathrm{h}$ ) at different locations in the treatment room are: A: 5.6, B: 5.5, C: 5.3, D: 8.5, E: 8.6, F: 8.5, G: 0.0002, and H: 0.0001, I: 0.0001 . Table 2 shows the neutron dose equivalent rate (again in $\mathrm{mSv} / \mathrm{h}$ ) at different locations in the treatment room (D to I), but for a fixed field size of $0 \times 0 \mathrm{~cm}^{2}$. At this field size, the neutron dose equivalent is maximum. The LINAC head was rotated down to the floor, and measurements were obtained at three locations (D, E, and F). Table 2 shows that the neutron dose equivalent measured on the floor is greater than the position measured at the treatment couch. At the other three locations $(\mathrm{G}, \mathrm{H}$, and I) outside of the treatment room, the dose rate equivalent was very low, ranging from 0.0001 to $0.0002 \mathrm{mSv} / \mathrm{h}$.

Table 1. Neutron dose equivalent rate $(\mathrm{mSv} / \mathrm{h})$ at locations $\mathrm{A}, \mathrm{B}$, and $\mathrm{C}$, as a function of field size.

\begin{tabular}{|c|c|c|c|}
\hline $\begin{array}{c}\text { Source Surface } \\
\text { Distance (SSD, cm) }\end{array}$ & $\begin{array}{l}\text { Point Measurement } \\
(x, y, z)\end{array}$ & $\begin{array}{l}\text { Field Size } \\
\qquad\left(\mathrm{cm}^{2}\right)\end{array}$ & $\begin{array}{c}\text { Neutron Dose } \\
\text { Equivalent Rate }(\mathrm{mSv} / \mathrm{h})\end{array}$ \\
\hline \multirow{3}{*}{100} & \multirow{3}{*}{$\mathrm{A}(0,0,0)$} & $0 \times 0$ & 6.31 \\
\hline & & $10 \times 10$ & 5.25 \\
\hline & & $20 \times 20$ & 4.56 \\
\hline \multirow{3}{*}{100} & $\mathrm{~A}(0,0,0)$ & \multirow{3}{*}{$10 \times 10$} & 5.25 \\
\hline & $\mathrm{B}(0,50,0)$ & & 5.50 \\
\hline & $C(0,100,0)$ & & 5.20 \\
\hline
\end{tabular}

Table 2. Neutron dose equivalent rate $(\mathrm{mSv} / \mathrm{h})$ at different locations on the floor $0 \times 0$.

\begin{tabular}{|c|c|c|}
\hline $\begin{array}{l}\text { Field Size } \\
\quad\left(\mathrm{cm}^{2}\right)\end{array}$ & Point Measurement $(x, y, z)$ & $\begin{array}{c}\text { Neutron Dose Equivalent } \\
\text { Rate }(\mathrm{mSv} / \mathrm{h})\end{array}$ \\
\hline \multirow{6}{*}{$0 \times 0$} & $\mathrm{D}(170,200,230)$ & 8.5 \\
\hline & $\mathrm{E}(-170,200,230)$ & 8.6 \\
\hline & $\mathrm{F}(170,0,230)$ & 8.5 \\
\hline & $\mathrm{G}(190,460,230)$ & 0.0002 \\
\hline & $\mathrm{H}(650,460,230)$ & 0.0001 \\
\hline & I $(850,460,230)$ & 0.0001 \\
\hline
\end{tabular}

Since the production of neutrons is unavoidable, an accurate measurement is necessary in order to estimate the risk of secondary cancer. As apparent in the literature, accelerators of various types yield different neutron spectra, a result of the variation in the materials used, variation in the interaction cross-sections, and beam geometry of the LINAC [12]. As the probability of secondary cancer is consequential, most particularly for pediatric and young adult cases, the neutron dose should be considered [12,16]. Figure 4 depicts the neutron dose rate equivalent distribution. The different values are based on the field size and location, and the average energies range from 1.0 to $2.0 \mathrm{MeV}$ [12] through to thermal energies of $0.025 \mathrm{eV}$. The biological effect of neutrons of higher quality factor results from neutrons with energies $\leq 2 \mathrm{MeV}$ [17-19]. 


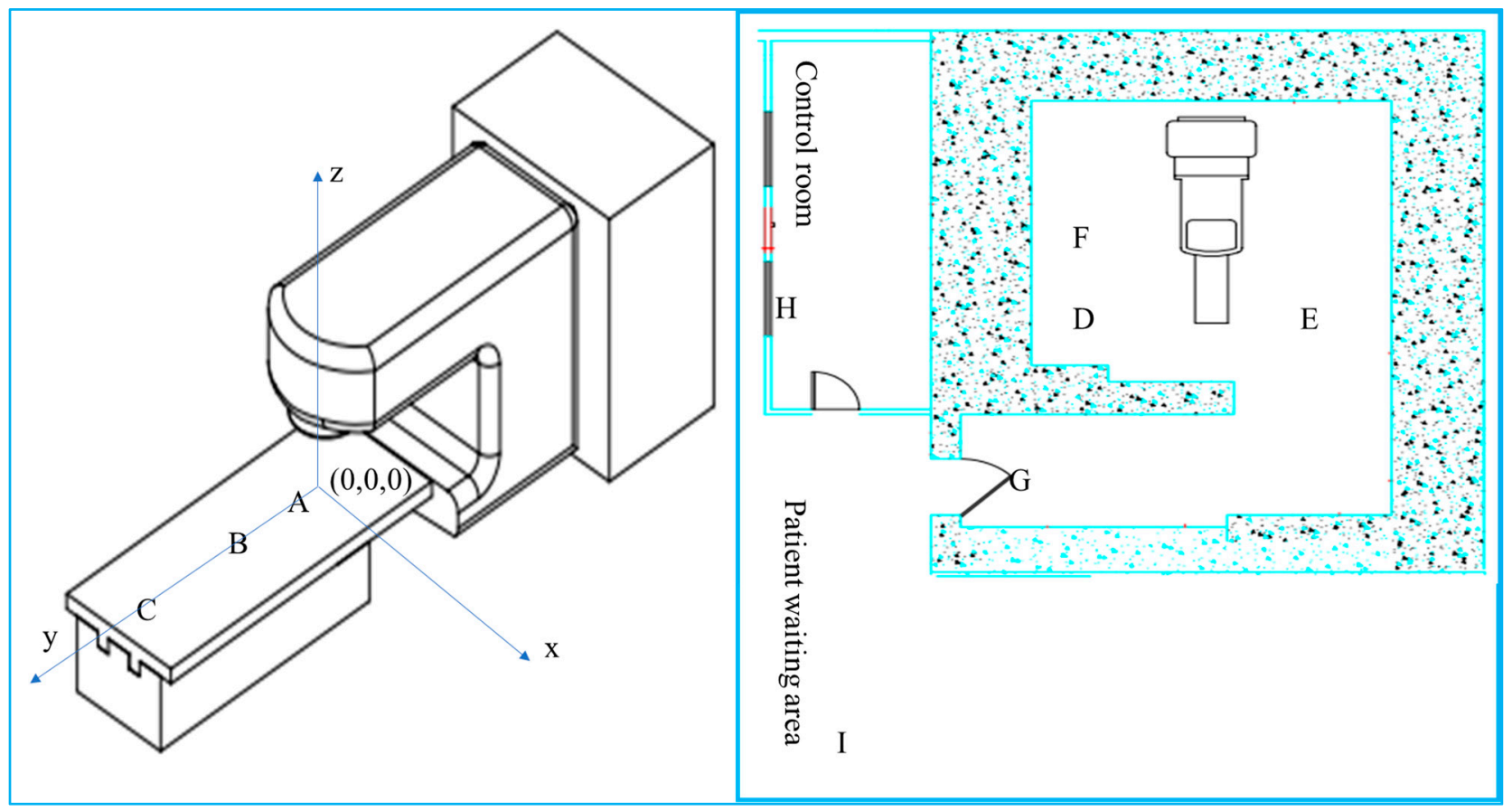

Figure 4. Equivalent dose rate $(\mathrm{mSv} / \mathrm{h})$ at different locations at the LINAC treatment room: A: 5.6, B: 5.5, C: 5.3, D: 8.5, E: 8.6, F: 8.5, G: 0.0002, and H: 0.0001, I: 0.0001. (left) Measurement points on the treatment table (A-C); (right) Measurement points on the floor $(\mathrm{D}-\mathrm{G})$, control room $(\mathrm{H})$, and patient waiting area (I).

The results for the radiation dose equivalent rate from the current study are comparable with the study by Barquero et al. [20]. Moving away from the isocenter, the energy of neutrons decreases, with the spectrum peak trending closer towards zero at the maze zone (Figure 4 and Table 2). With this, the current study provides valuable data for neutron distribution within the treatment room, which is important in improving patient safety through the provision of protective measures.

\section{Conclusions}

The current study concerns the neutron dose resulting from the operation of a Siemens Primus M5497 electron accelerator, which is operated in the photon mode at $15 \mathrm{MV}$. The results show that the radiation dose equivalent rate depends on the field size. In practical terms, this rate is independent of the position along the y-axis. The dose at the ground level has been found to be markedly greater than the isocenter, most prominently when the jaws are closed rather than open. The dose rate equivalent outside of the bunker was found to be very low, ranging from 0.0001 to $0.0002 \mathrm{mSv} / \mathrm{h}$. The neutron dose equivalent rate in the LINAC treatment room is essential in informing matters concerning the adequacy of shielding, in improving patient protection, and in seeking to mitigate the risk of secondary cancer.

Author Contributions: Conceptualization, D.T.T. and T.T.H.L.; methodology, D.T.T. and T.T.H.L.; software, D.T.T., T.T.H.L. and H.O.; validation, D.T.T., T.T.H.L., A.S.; formal analysis, D.T.T. and D.A.B.; investigation, D.T.T. and T.T.H.L.; resources, N.T. and H.O.; data curation, D.T.T., A.S. and H.O.; writing-original draft preparation, A.S. and H.O.; writing-review and editing, D.A.B. and A.S.; visualization, N.T.; supervision, T.T.H.L. and D.A.B.; project administration, N.T.; funding acquisition, A.S., N.T. and D.A.B. All authors have read and agreed to the published version of the manuscript.

Funding: The authors extend their appreciation to the Deanship of Scientific Research at Prince Sattam Bin Abdulaziz University for funding this work through the Research Leadership Program (RLP-2021). 
Institutional Review Board Statement: Not applicable.

Informed Consent Statement: Not applicable.

Data Availability Statement: Data available on request from the authors.

Acknowledgments: The first and second authors would like to extend their gratitude to the Director of Dong Nai General Hospital and Head of Radiation Oncology for their support, and the Nuclear Technique Laboratory, University of Science, Ho Chi Minh City, Vietnam for the use of the dosimeter. This research is supported by the Ho Chi Minh City University of Technology and Education (HCMUTE), Vietnam.

Conflicts of Interest: The authors declare no conflict of interest.

\section{References}

1. Sung, H.; Ferlay, J.; Siegel, R.L.; Laversanne, M.; Soerjomataram, I.; Jemal, A.; Bray, F. Global Cancer Statistics 2020: GLOBOCAN Estimates of Incidence and Mortality Worldwide for 36 Cancers in 185 Countries. CA Cancer J. Clin. 2021, 71, 209-249. [CrossRef] [PubMed]

2. Pucci, C.; Martinelli, C.; Ciofani, G. Innovative approaches for cancer treatment: Current perspectives and new challenges. Ecancermedicalscience 2019, 13, 961. [CrossRef] [PubMed]

3. Baskar, R.; Lee, K.A.; Yeo, R.; Yeoh, K.-W. Cancer and Radiation Therapy: Current Advances and Future Directions. Int. J. Med. Sci. 2012, 9, 193-199. [CrossRef] [PubMed]

4. Gianfaldoni, S.; Gianfaldoni, R.; Wollina, U.; Lotti, J.; Tchernev, G.; Lotti, T. An Overview on Radiotherapy: From Its History to Its Current Applications in Dermatology. Maced. J. Med. Sci. 2017, 5, 521-525. [CrossRef] [PubMed]

5. Anderson, I.; Andreani, C.; Carpenter, J.; Festa, G.; Gorini, G.; Loong, C.-K.; Senesi, R. Research opportunities with compact accelerator-driven neutron sources. Phys. Rep. 2016, 654, 1-58. [CrossRef]

6. $\quad$ Eaton, B.R.; Macdonald, S.M.; Yock, T.I.; Tarbell, N.J. Secondary Malignancy Risk Following Proton Radiation Therapy. Front. Oncol. 2015, 5, 1-6. [CrossRef] [PubMed]

7. $\mathrm{Ng}$, J.; Shuryak, I. Minimizing second cancer risk following radiotherapy: Current perspectives. Cancer Manag. Res. 2015, 7, 1-11. [CrossRef] [PubMed]

8. Konig, L.; Haering, P.; Lang, C.; Splinter, M.; von Nettelbladt, B.; Weykamp, F.; Hoegen, P.; Lischalk, J.W.; Herfarth, K.; Debus, J.; et al. Secondary Malignancy Risk Following Proton vs. X-ray Treatment of Mediastinal Malignant Lymphoma: A Comparative Modelling Study of Thoracic Organ-Specific Cancer Risk. Front. Oncol. 2020, 10, 989. [CrossRef] [PubMed]

9. Hoffman, K.E.; Yock, T.I. Radiation Therapy for Pediatric Central Nervous System Tumors. J. Child Neurol. 2009, 24, 1387-1396. [CrossRef] [PubMed]

10. Hall, E.J. Intensity-modulated radiation therapy, protons, and the risk of second cancers. Int. J. Radiat. Oncol. Biol. Phys. 2006, 65, 1-7. [CrossRef] [PubMed]

11. Ekendahl, D.; Bečková, V.; Zdychová, V.; Bulánek, B.; Prouza, Z.; Štefánik, M. Accidental neutron dosimetry with human hair. Radiat. Phys. Chem. 2014, 104, 80-83. [CrossRef]

12. Farhood, B.; Ghorbani, M.; Goushbolagh, N.A.; Najafi, M.; Geraily, G. Different Methods of Measuring Neutron Dose/Fluence Generated During Radiation Therapy with Megavoltage Beams. Health Phys. 2020, 118, 65-74. [CrossRef] [PubMed]

13. Howell, R.M.; Kry, S.F.; Burgett, E.; Hertel, N.E.; Followill, D.S. Secondary neutron spectra from modern Varian, Siemens, and Elekta linacs with multileaf collimators. Med. Phys. 2009, 36, 4027-4038. [CrossRef] [PubMed]

14. Followill, D.S.; Stovall, M.S.; Kry, S.F.; Ibbott, G.S. Neutron source strength measurements for Varian, Siemens, Elekta, and General Electric linear accelerators. J. Appl. Clin. Med. Phys. 2003, 4, 189-194. [CrossRef] [PubMed]

15. Naseri, A.; Mesbahi, A. A review on photoneutrons characteristics in radiation therapy with high-energy photon beams. Rep. Prac. Oncol. Radiother. 2010, 15, 138-144. [CrossRef] [PubMed]

16. Peña, J.; Franco, L.; Gómez, F.; Iglesias, A.; Pardo, J.; Pombar, M. Monte Carlo study of Siemens PRIMUS photoneutron production. Phys. Med. Biol. 2005, 50, 5921-5933. [CrossRef] [PubMed]

17. Lin, J.-P.; Liu, W.-C.; Lin, C.-C. Investigation of photoneutron dose equivalent from high-energy photons in radiotherapy. Appl. Radiat. Isot. 2007, 65, 599-604. [CrossRef] [PubMed]

18. Schauer, D.; Linton, O.W. National Council on Radiation Protection and Measurements Report Shows Substantial Medical Exposure Increase. Radiology 2009, 253, 293-296. [CrossRef] [PubMed]

19. Ma, A.; Awotwi-Pratt, J.; Alghamdi, A.; Alfuraih, A.; Spyrou, N.M. Monte Carlo study of photoneutron production in the Varian Clinac 2100C linac. J. Radioanal. Nucl. Chem. 2007, 276, 119-123. [CrossRef]

20. Barquero, R.; Mendez, R.; Vega-Carrillo, H.R.; Iñiguez, M.P.; Edwards, T.M. Neutron spectra and dosimetric features around an $18 \mathrm{MV}$ linac accelerator. Health Phys. 2005, 88, 48-58. [CrossRef] [PubMed] 